\title{
ON THE RELATIONS
}

\author{
BETWEEN
}

\section{BODILY DEVELOPMENT, NUTRITION, AND BRAIN CONDITIONS}

\section{IN THEIR PATHOLOGICAL ASPECTS}

BY

FRANCIS WARNER, M.D.Lond., F.R.C.P., F.R.C.S.Eng., PHYSICIAN TO, AND LECTURER ON THERAPEUTICB AT, THE LONDON HOSPITAL

Received November 25th, 1896-Read May 11th, 1897

THE purpose of this paper is to show, as the result of extended observation among children, that-

(1) Points of abnormal development in the body are very common, and have important signification.

(2) Abnormal nerve-signs, or points in balance and movement, have been defined; they are much associated with defective development, as well as with the causes of mental dulness, and are of clinical importance.

(3) There is an intimate empirical relation between (A) Defective development; (B) Abnormal nerve-signs;

(c) Low nutrition and health of the body and its tissues ;

(D) Mental dulness and backwardness. 
(4) Some explanation of the relations among the classes of defect may be offered on the hypothesis of evolution (and dissolution of co-ordination) resulting from action of the environment.

Certain propositions will be put forward, supported by evidence accumulated.

Experience gained among children shows many typesand groups of cases of clinical significance. All observers are familiar with ill-made heads and features; delicacy without disease; nervousness and nerve disorderliness without known structural changes; children with antics, abnormal gestures, awkward habits in balance of body, in movement, in speech ; children mentally dull or backward ; and cases of varied grades of cerebral deficiency. It is always useful to study common conditions such as are frequently met with, and by careful accumulation and arrangement of facts some problems of importance in pathology may be explained.

The facts concerning conditions of bodily development below the normal, and indications of defective nerve status as se commonly seen, supply data for the more accurate study of what is sometimes called the constitutional or general condition of the subject examined; while their fuller appreciation appears to throw considerable light upon such problems as the causes of infant mortality, the differences between the sexes, the genesis of neurotic conditions, feeble health without disease, and the many causes of mental dulness and deficiency.

In a paper read before this Society in 1882, "On Postures of the Hand as Indications of the Condition of the Brain," I put forward certain principles for the anatomical analysis of the typical postures described, and the usefulness of such points as clinical signs was discussed. After further observation and study they were applied in an inquiry as to the mental and physical conditions of children in schools; their signification has since been further determined.

In 1888 a Committee of the British Medical Association 
was formed to conduct an investigation as to the average development and condition of brain power anong the children in primary schools; and between 1888-94 I had the opportunity of examining 100,000 children individually in schools, in conjunction with other medical men. My thanks are particularly due to Dr. G. E. Shuttleworth, Dr. Fletcher Beach, Dr. T. L. Rogers, Dr. Henry Rayner, and the late Dr. D. H. Tuke, for their kind assistance.

The children were examined as they stood in rank, each being viewed systematically; they were required to make a few simple movements, and all points below the normal both in body and in action were noted. The same points were looked for in each child. The teacher's report as to mental ability was recorded in each case. In this manner a written account in schedules was taken of 18,127 cases in some respect below normal. The results of observation have been published in a report: ${ }^{1}$ the 104 signs described in the cases have been defined in a nomenclature; while the cases presenting the classes of defect are analysed and arranged so as to show their relations to one another for the sexes in age groups.

Four main classes of defect were thus recorded:

(A) Defect in development : in size, form, proportions of parts of the body.

(B) Abnormal nerve-signs : abnormal balance and action, or reaction in movement and co-ordination.

(c) Low nutrition : cases pale, thin or delicate.

(D) Cases dull or backward mentally, as reported by the teachers.

Taking these records as a basis of facts, analysis and research has supplied much information as to the relations between bodily development, nutrition of body, and brain conditions in their pathological aspects; as found among boys and girls respectively in the age groups.

1 ' Report on the Scientific Study of the Mental and Physical Conditions of Childhood, with particular reference to children of defective constitution; and with recommendations as to education and training. Based on the examination of 100,000 children, 1888-94.' Published by the Committee, Parkes' Museum, Margaret Street, London, W. 
The more common points observed as defects in bodily development numbered forty-two, besides miscellaneous examples, such as congenital defects of the eyes and the grosser deformities of the body. The principal signs are in size, form, and proportions of the cranium, palate, external ear, and the features individually, as well as in stature and growth. The relative importance of each defect varies; the association with other classes of defect standing highest where the cranium is ill-made, the palate standing next in value. These individual corelations are given in Table XVI of the report.

When two or more developmental defects are present in the same case, the co-relation with other classes of defect rises (see Table XVIII in Report).

The more common abnormal nerve-signs described numbered twenty, besides such less common defects as tremor, ptosis, and other paralyses. These signs are abnormal modes of muscular balance, movement and reaction in movement; they are seen in the head, spine, shoulders, and planting of the feet and balance of the upper extremities; while as finer movements we observe the nerve-muscular balance and movements of the hands and digits, movement of the eyes, together with the expression, muscular tone, and movement in the frontal middle region and lower part of the face.

In dealing with a large number of cases facts must necessarily be recorded by the aid of figures. In the report published and elsewhere, ${ }^{1}$ results of statistical analysis are fully given; they form a basis of facts here quoted, and need not be repeated. In all such modes of dealing with accumulated cases the boys and girls are kept separate. Another important point as regards the 50,000 children seen, 1892-4, is the method of dealing in statistics with "primary groups of cases ;" that is, with groups in which observation showed the presence of the class of defect named, and absence of the other classes of

1 See author's paper, 'Journal of Royul Statistical Society,' March, 1893, and March, 1896; Reports to British Association, 1894-6. 
defect. This has made it possible to trace with some degree of accuracy the interaction of the various forms of defect as referred to in evidence for the propositions. Cases are arranged not only in primary groups as above; they are also presented as " compound groups," containing all the cases with the class or classes of defect named. Thus Primary Group A contains all cases with defect in development only without nerve-signs or low nutrition; while the Compound Group $A^{1}$ contains all the cases with defect in development, whether they have also nerve-signs and low nutrition or not. These compound groups are necessarily larger than the corresponding primary group. The facts derived from the results of the inquiry are sufficiently shown in the tables appended; they deal only with the 50,000 children seen, 1892-4, giving an analysis of all cases with developmental defect; abnormal nervesigns or low nutrition, whether dull pupils or not. The facts concerning mental dulness are here omitted.

Table I shows the primary group, or groups presenting only the class or classes of defect named, presented as sub-classes comprising the total number of cases noted. Cases are arranged in three columns as age groups; and in the fourth column for children of all ages. In the first four columns the primary groups are distributed as percentages of the total number of cases noted respectively; in the last column the distribution is in percentages upon the total number of children seen.

Table II shows the compound groups, containing all the cases of the class or classes of defect named, whether alone or in combination with other defect.

The groups are presented in columns as in Table I, and the percentages are similarly distributed.

Table III shows the co-relations of the classes of defect or the association of the groups of cases with other class or classes of defect named, in the form of percentages, whether alone or in combination with other defect.

Table IV shows the primary groups as components of 1 Ibid. 
the compound groups which contain all the cases with the class of defect named. The number of cases is given ; while the primary groups are distributed as percentages on the number in the compound groups respectively.

In explanation of the tables the information given as to the associations of developmental defect, for children of all ages, may in part be traced. In Table I it is shown that such cases alone, without either nerve-signs or low nutrition, formed 26.9 per cent. of the boys and 17.5 per cent. of the girls noted as cases with some defect; and 4.5 per cent. of the boys and 3.2 per cent. of the girls seen in schools. In Table II it is shown that developmental cases alone or in combination with nerve-signs and low nutrition formed 26.9 per cent. of the boys and $23 \cdot 6$ per cent. of the girls noted with some defect; and 8.7 per cent. of the boys and 6.8 per cent. of the girls seen in schools. In Table III it is shown that of the developmental cases 38.4 per cent. of the boys and $36^{\circ} 3$ per cent. of the girls respectively presented abnormal nerve-signs ; while of the boys $16 \cdot 2$ per cent., and of the girls 26.5 per cent., were pale, thin, or delicate.

In Table IV the numbers of boys and girls with developmental defects only, and the total numbers with such class of defect, are shown; while the percentages show the proportions of the primary group to the compound group.

In studying these records of the common defects of childhood the statistical method shows the existence of important relations among the classes of defect; and shows further, that a clinical value may be attached to the signs by which the groups of cases are classified. Arguments in explanation of the co-relations demonstrated may afford some explanation of the significance of the developmental defects and abnormal nerve-signs. In studying the physiology of man, and the pathology of his parts or organs, we consider growth, function, change and decay in the part or organ and in the cells composing its structure (cellular pathology). So in studying the 
brain we wish to observe function and change in its parts -the nerve-centres, cells, and fibres. I wish here to suggest the importance of noting the attributes time and quantity of the growth, or action, in the living part observed, as part of the natural phenomena recorded. ${ }^{1}$

Analogy or comparison between objects or phenomena is one of the means of giving explanation, and is admissible in scientific argument if the points of comparison as observed are accurately described. What common points for comparison are to be found between examples of maldevelopment or disproportioning in the growth of the parts of the body and abnormal modes of action in the brain-centres? A careful analysis of the signs observed in defective development and the abnormal nerve-signs shows that we may logically compare relations in proportional growth with relations in quantity of nerve-action; and relations in the time of growth with relations in the time of action in nerve-centres.

The signs of defective development can be shown to consist mainly of disproportion in growth, the ratios of growth in the parts of the features are not normal; this is a relation in the quantities of growth, abnormal under the rction of inherited or present effects of the environment. As an example, the external ear may be large, outstanding, coarse-looking. Analysing the parts of such an ear we usually find that growth has been greater on the posterior than on the anterior surface, and the outstanding ear is a mechanical result of such proportions in growth; further, the ante-helix is absent, and the helix in great part is wanting, another abnormality in the proportions of growth. The ratios of growth in the parts of the ear are less varied, and not the normal. Such an outstanding ear is probably a better sound collector than the normal ear; at any rate sound waves are better collected in a normal ear by

1 See author's 'Physical Expression,' International Scientific Series. - Anatomy of Movement: a Treatise on the Action of Nerve-centres and Modes of Growth.' 
holding it forward and mechanically unfolding the antehelix. The normal ear cannot be said to have evolved in its mode of growth to produce better hearing, but is the result of complex ratios in growth. These abnormal external ears are far more common in boys than in girls; the male always tends more to variation in bodily development. Of cases with abnormal ears 54.0 per cent. of the boys and $47 \cdot 7$ per cent. of the girls presented abnormal nerve-signs.

'The physical signs indicating the mode of action among the nerve-centres express relations as to time and quantity of action. In a normal child the balance or posture assumed by the hands when held out free in front of him to the word of command, or in imitation of the action in the observer, is with the forearm pronate, the arms being straight at the elbow, horizontal on a level with the shoulder and parallel to one another the width of the chest apart, while the wrist is straight extended, and all parts of the hand are balanced in the same plane, both the metacarpal bones and the digits. Such was the type of hand balance seen in 94.8 per cent. of the boys and 95.4 per cent. of the girls in the schools.

In a paralysed arm without rigidity, or, better, in a heulthy arm during deep sleep, when the brain is not, innervating the muscles, if the forearm be held passively horizontal it will droop at the wrist, the metacarpal bones folded together or adducted while the digits are moderately flexed. In the child just convalescent from chorea the hand when held out droops in flexion, the metacarpus being slightly adducted while the metacarpo-phalangeal joints are extended backwards beyond the straight line, the fingers being slightly flexed. In this nervous hand posture there is a difference of balance both from the normal straight hand and the adynamic hand of paresis; we infer altered ratios of action among the nerve-centres. The centres for wrist extension are weakened while there is over-action in the centres for the small muscles extending the knuckles; there is an altered ratio of action 
indicated by the posture, and those ratios are not normal. Unequal bilateral cerebral action is indicated when the head habitually drops to one side, and when the left arm is held at a lower level than the right, with the hand more in the adynamic posture, as is very commonly seen in weak subjects.

Twitching of individual fingers, whether flexor-extensor as produced by the muscles of the forearm, or lateral as produced by the smaller intrinsic muscles of the hand, are indications of temporary and often uncontrolled discharge in the nerve-centres expressing their frequency and rapidity, or other relations in time of action.

Co-ordination consists in the regulation of the attributes time and quantity of the individual movements of an action; and consequently in control of these attributes in the motor action of the nerve-centres in certain combinations and series of combinations.

Movements may be conveniently classified for clinical observation as series of acts, according to their relations in time, thus-

1. Uniformly repeated series of movements. The same parts moving in similar combinations and series of acts on successive occasions, often recurring on any stimulation through the senses. Over-action of the frontal muscles in children of cerebral deficiency is a type of such mode of movement, producing horizontal creases in the forehead which may be coarse or fine but are constantly repeated; the frontal muscles are sometimes seen working under the skin in vermicular fashion with an athetoid movement. Repeated grinning is an example of an action of this class; while in the athetosis of hemiplegia we see uniformly repeated series of movements uncontrolled by impressions through the senses, and therefore useless and purposeless.

2. Augmenting series of movements. The area of movement spreading from part to part either spontaneously or on any stimulation, the number of parts in movement increasing; such mode of action in a normal brain may 
be indicative of mental excitement or emotion. The area of parts moving may spread in the face, then to the digits of one hand or both hands, just as the march of spasm is seen in epilepsy and with some cerebral lesions. Such augmenting series of movements are often seen on approaching a choreic child, especially when he is spoken to. In other cases an extra series of uniformly repeated movements may accompany co-ordinated action, as when the child writes his name, the action being accompanied by over-action of the frontal and corrugator muscles. The question asked, or the commencement of any (voluntary) action may be accompanied by protrusion of the tongue, bending of the head to one side, fidgeting extra and uncontrolled movements of the fingers; analogous extra movements may occur in wandering of the eyes.

3. Diminishing series of movements. A diminishing area of movements, and number of movements, corresponding to a diminishing number of nerve-centres in action, is seen as sleep approaches, or excitement or a storm of passion subsides; as the epileptic attack passes off; or as we watch a child day by day when recovering from chorea.

4. Co-ordinated movements. A series of movements controlled or adapted by impressions received. In a clinical examinatiou the child may be asked to imitate movements with one or with both hands as made before him; he does so through the agency of sight. If his movements, as controlled through his eye, are the same as those imitated, alike in the time and the quantity of movements of parts, he is said to perform good coordinated movements.

The only characters of a movement are its attributes time and quantity, together with its antecedents and sequents.

In what respects, then, does a child with abnormal nerve-signs show abnormal brain action? The four classes of movements are described as to their relations in the attributes time and quantity of action; the same attributes as characterise modes of growth in parts of 
the body as normal or abnormal. Let us take some examples. Response to a question or in imitation of movement may be delayed, then we see the action slow or abnormal in relation of time. In uniformly repeated movements, and in the occurrence of extra movements, abnormality in action of the nerve-centres is in relation of time. In abnormal balance of the hand we see the ratios, or relations in quantity of action in the nervecentres respectively, indicating the abnormal or imperfect nerve status; this may affect centres for the larger or the smaller muscles.

The inference from the observed co-relation of develop: ment defect with the nerve-signs is that when the proportions in growth of parts of the body are abnormal (relations in quantity), whether as the result of inheritance or of impressions received, the nerve-centres are commonly so built up that in subsequent action they do not work, under the influence of the environment, in normal relations of time and quantity. This defective mode of action among nerve-centres may apply equally to motor and mental function.

Following the lines of the hypothesis of an evolution of living beings under the action of their environment, an attempt may be made to analyse, or in part unravel, some factors in the ætiology of irregular bodily development and nerve status.

It has been shown that the defects in development are disproportioning in parts of the body which is mainly a relation in the ratios of growth or their delay or arrest; while the abnormal nerve-signs are the expression of abnormal relations in the quantity or the time of action in the nerve-centres producing the balance or movement seen.

Each class of signs is then essentially due to defective relations in time or quantity of action as controlled by the environment; it has been shown that the two classes of defect are co-related, and when so associated in a persistent form they are apparently dependent upon, or vol. LXXX. 
sequential to, circumstances which affected both the ratios of development in parts of the body and the building up of the nerve-centres.

It has been shown that defects in bodily development are much associated with conditions of low nutrition; such children being pale, thin, or delicate. This fact seems to indicate that such environment as leads to disproportioning in growth leads also to a status of the tissues prone to atrophy under adverse circumstances. This, I know not why, is specially found anong girls, and acts very unfavorably on their neural conditions; hence the great liability among girls of mal-development to acquire nerve disturbance taking a more permanent form than among boys.

Inco-ordinated nerve action without structural changes, is mainly a state in which the time and the quantity of action in nerve-centres is abnormal as it occurs under control (or want of control) of the environment. In some cases, as in child-fidgetiness over spontaneous action, and in chorea, it appears that the mode of action anong the nerve-centres reverts to the spontaneity and the incoordinated condition of brain which is normal in the infant, as evidenced by the large number of spontaneous movements of all parts which characterises the healthy child during the early months of life (microkenesis ${ }^{1}$ ).

Further facts in evidence are given in the following propositions.

Proposition I.-Disproportioned bodily development is very common; it is co-related with low nutrition of body and inco-ordinated brain action.

The facts concerning the association of mal-development with low nutrition of body are demonstrated in the tables, and in the explanation of them already given. This corelation is highest (see Table III) with the girls in all age groups, and is specially marked among the children

1 See 'Proceedings of the Royal Society,' vol. xliv, and 'Journal of Mental Science,' April, 1888. 
of seven years and under; this co-relation is much lower at eleven years and older. On the other hand, the corelation of developmental defect with nerve-signs increases with age for girls, less so with boys. Finally, the proportion of the developmental cases that have not acquired either low nutrition or nerve-signs is highest for boys in the oldest group; while for girls it remains about the same in each age group (see Table IV). This seems an indication that the environment is apt to produce more harm and less good in girls than in boys of imperfect development.

Proposi'rion II.-Inco-ordinated brain action is much associated with mal-development; and the presence of nervesigns is more co-related with the causes of mental dulness than are the signs of defective development.

The tables show the co-relation of nerve-signs with mal-development (Table III) as highest for children of seven years and under, and lowest in the oldest groups; while the proportion of nerve cases that have nerve-signs only without developmental defect or low nutrition (Table IV) is highest with the oldest group ; the environment appears to favour the occurrence of simple cases of nerve inco-ordination and weakness; these in many instances might be removed by training. Although the facts concerning mental dulness are not included in the tables here given, it may be stated that the presence of abnormal nerve-signs, indicating inco-ordination of brain, is more closely related to the causes of mental dulness than are the defects in bodily development. ${ }^{1}$

Proposition III.-Delicate children are in a large proportion of cases ill-developed in some part of the body.

The relation between delicacy, as indicated by the child being pale or thin, and mal-development is not as strongly marked in boys as in girls, and the co-relation varies in the age groups. Among children without developmental

' See 'Mental Faculty,' Cambridge University Press. 
defect there does not seem to be a larger proportion of delicate girls than boys; it is the girl who has some defect that is delicate, not all girls. In this co-relation there is very little difference whether nerve-signs are present or not; I conclude, therefore, that the low nutrition in developmental cases is not a direct effect of the accompanying brain disorderliness. It is interesting to find that ill-developed children remain thin and delicate in all social classes and among those well supplied with food; in resident institutions, where there is but little mental excitement, the associated delicacy is least marked. 
NUTRITION, AND BRAIN CONDITIONS

365

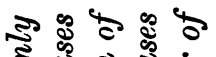

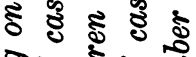
స कू है हี

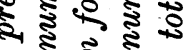

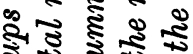

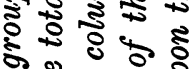
$2 \pi)^{2}$ $2 \pi \frac{\pi}{2} \sqrt{2}$ की 2.

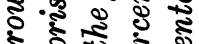
के हॉत इ

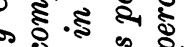

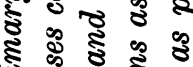

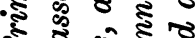
मे गे है ह స్

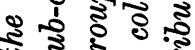
क के के హิ \& -

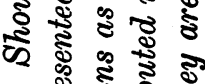
. है हิ స్ స

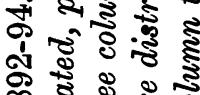

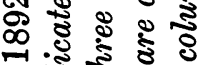

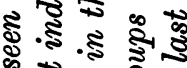
2.

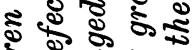

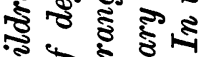
స్ \&

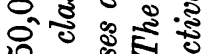

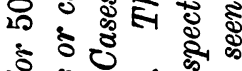

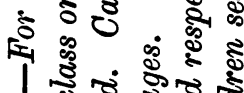

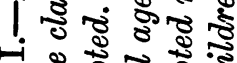
芳范

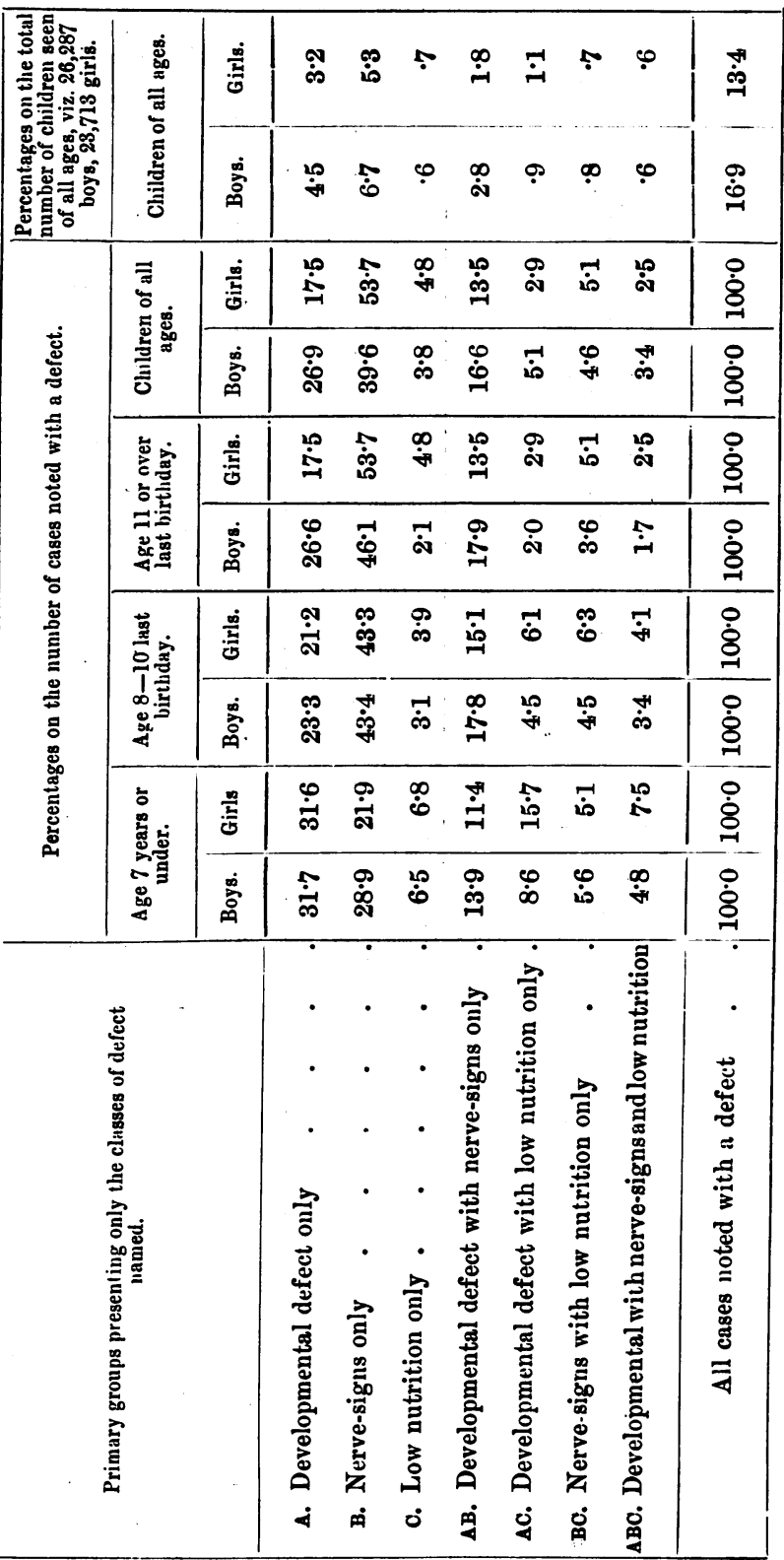




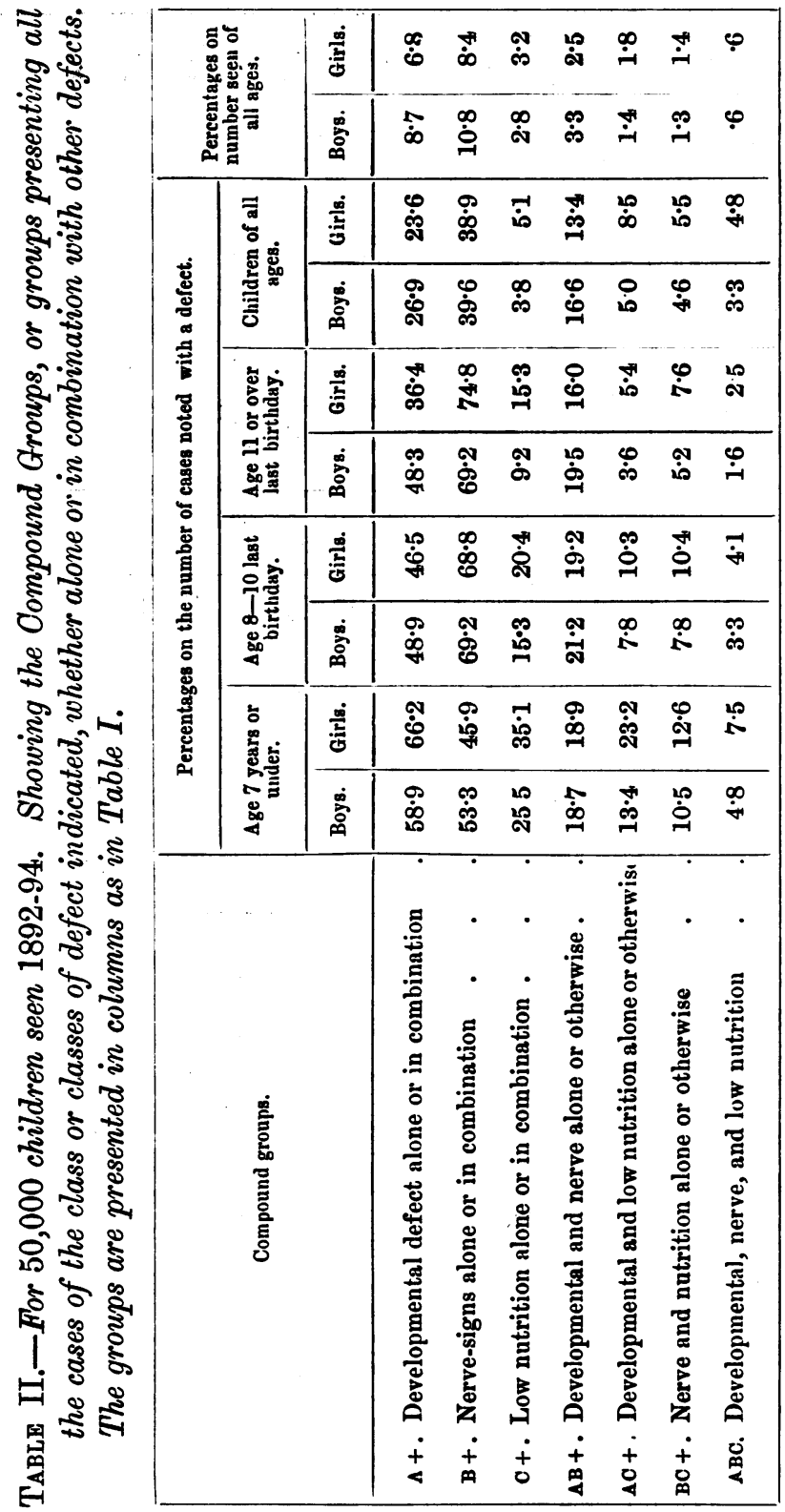


NU'IRITION, AND BRAIN CONDITIONS

367

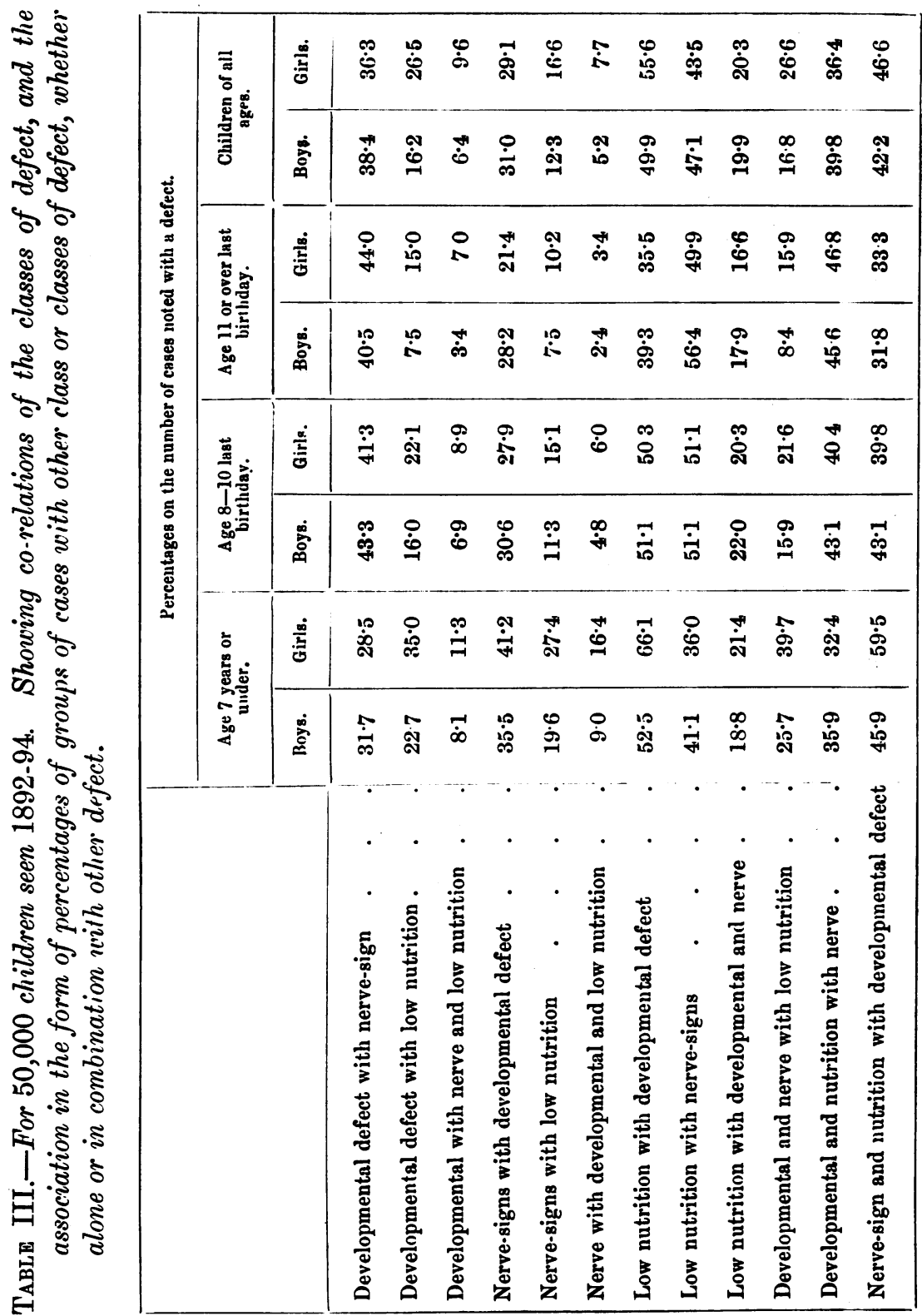




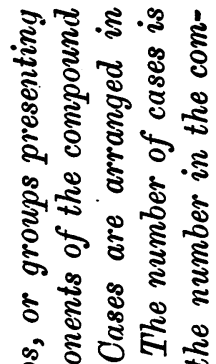

हิ हो

हूँ हैं के

\% हू के \&

T)

ช శู

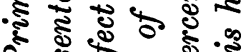

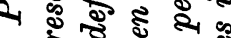

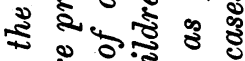

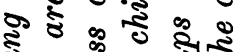

- त्रे రิ कर स्ञ है है

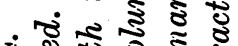

मi

ด.

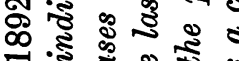

$\approx$ ป

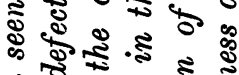

胥

స \& क का

స్

8)

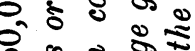

मी

โิ

1 尔

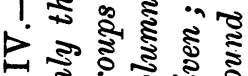

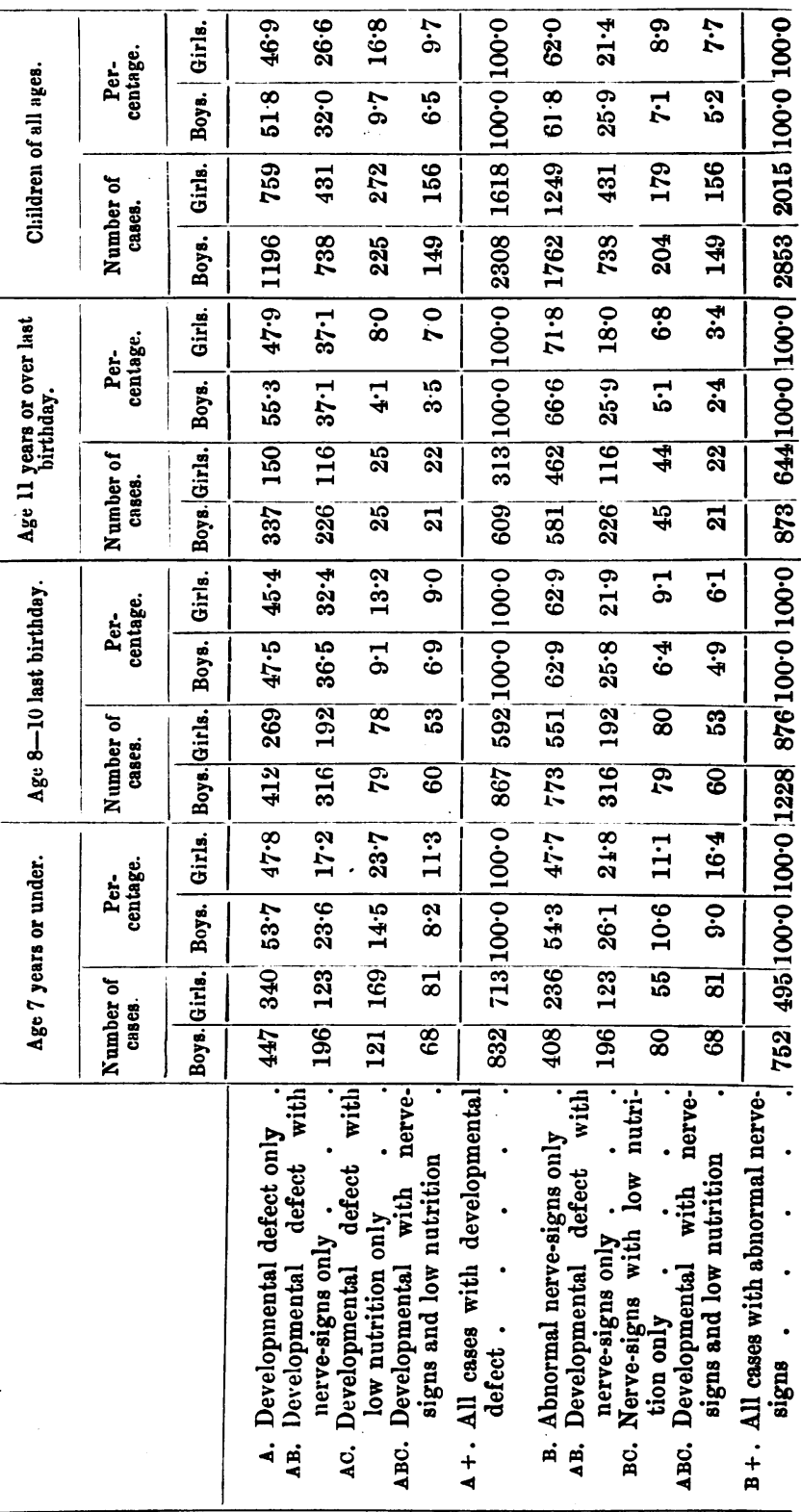

定 ปิ ถิ 


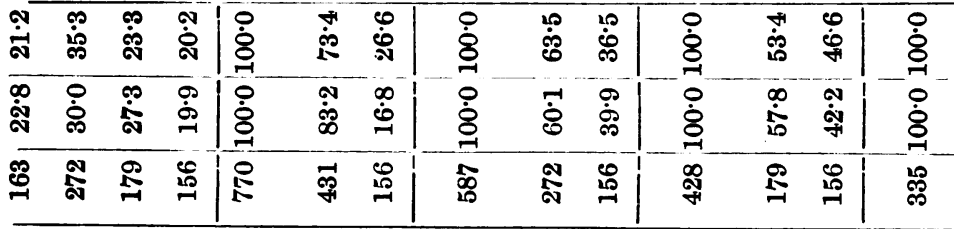

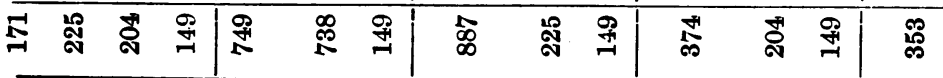

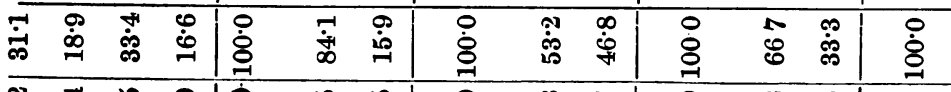

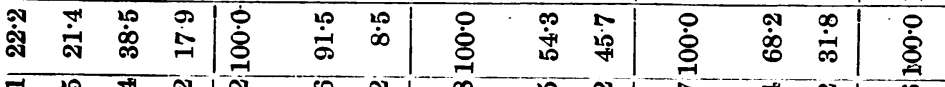

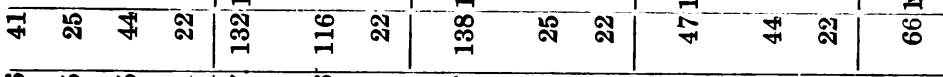

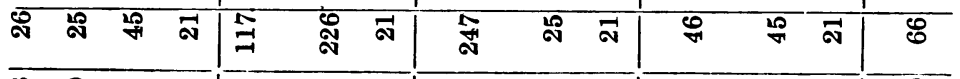

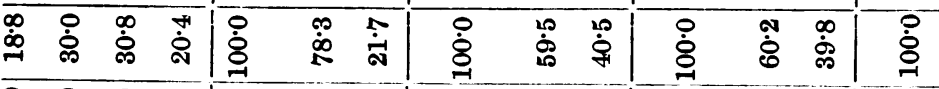

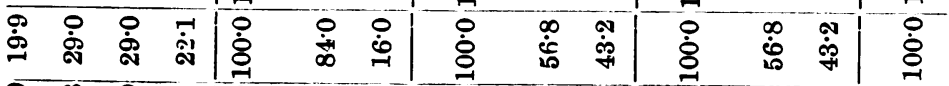
क 苛页

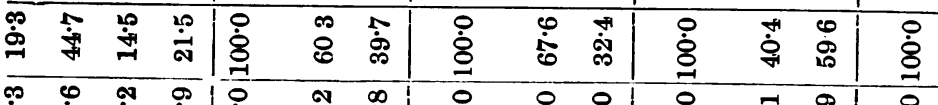

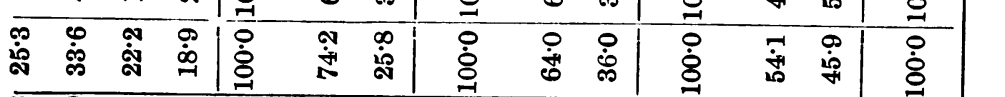

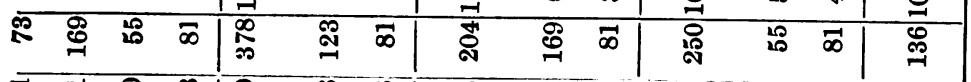
क অ

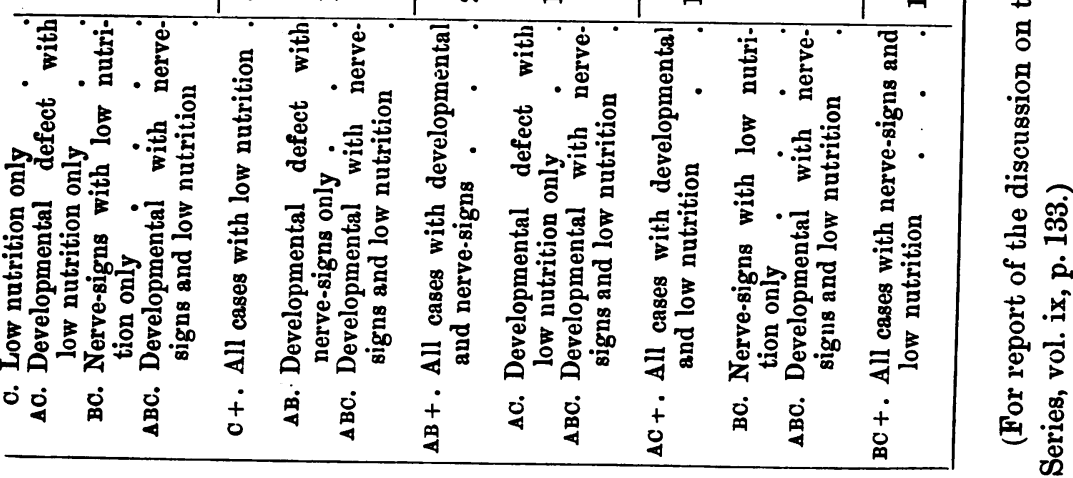

